\title{
AN UPDATE ON PHARMACOLOGICAL PROFILE OF BOSWELLIA SERRATA
}

\author{
NAMEETA PILKHWAL ${ }^{1}$, SUNEELA DHANESHWAR ${ }^{2 *}$
}

${ }^{1}$ Department of Pharmacology, Amity Institute of Pharmacy, Amity University Uttar Pradesh Lucknow Campus, Lucknow, Uttar Pradesh, India. ${ }^{2}$ Department of Pharmaceutical Chemistry, Amity Institute of Pharmacy, Amity University Uttar Pradesh Lucknow Campus, Lucknow, Uttar Pradesh, India. Email: sdhaneshwar1@lko.amity.edu

Received: 27 September 2018, Revised and Accepted: 01 April 2019

\begin{abstract}
Boswellia serrata (Burseraceae) is one of the oldest and most explored herbs in Ayurveda. In Unani system of medicine, oleo-gum resin of B. serrata named Kundur has been a key component of modern quality perfumes. The gum is used as a remedy for the treatment of illness especially skin diseases and rheumatism in Indian system of medicine (Siddha, Ayurvedic, and Unani) for the preceding centuries. Salai guggul is one of the accepted drugs for various complaints such as dyspepsia, dysentery, lung diseases, urinary disorder, hemorrhoids, and corneal ulcer in Unani system of medicine for the past few decades. The present article is aimed to provide an overview on various pharmacological activities of $B$. serrata. The resin fraction of Salai guggal is rich in boswellic acids and its essential oils that are composed of a mixture of mono-, di-, and sesqui-terpenes while gum fraction chiefly contains pentose and hexose sugars. The oleo-gum resin is highly sought after by the practitioners of traditional system because it has shown broad range of efficacy in asthma, cancer, microbial/fungal infections, hyperlipidemia, inflammation, arthritis, diarrhea, and management of pain. An exhaustive review of literature was conducted using various databases on ScienceDirect, Scopus, PubMed, Google Scholar, and Free Patents online. This review is a sincere attempt to discuss and present the current status of pharmacological profile of $B$. serrata.
\end{abstract}

Keywords: Boswellia serrata, Inflammation, Boswellic acids, Leukotriene synthesis, Pharmacology.

(C) 2019 The Authors. Published by Innovare Academic Sciences Pvt Ltd. This is an open access article under the CC BY license (http://creativecommons. org/licenses/by/4. 0/) DOI: http://dx.doi.org/10.22159/ajpcr.2019.v12i5.31260

\section{INTRODUCTION}

Boswellia serrata (Fig. 1) (Kundur) is commonly known as "Salai guggal" owned by the family Burseraceae. The tree is commonly found in Southern Arabia, West Asia, Oman, South Africa, and Yemen. In India, it is widely distributed in Western Himalayas, Madhya Pradesh, Gujarat, Orissa, Rajasthan, Bihar, and Maharashtra. It is a moderate to large deciduous tree with a circumference of $2.4 \mathrm{~m}$ and medium height of 4-5 m. The papery bark changes its color from greenish-gray, yellow, or reddish to ash color which can be easily peeled off. On peeling or incision, the barks secrete an exudate in the form of translucent lumps, tears, or droplets of white to yellow-colored gummy oleo-gum resin. The aromatic gum has balsamic odor and bitter taste. In Ayurveda, an Indian traditional system of medicine, the gum is used for the treatment of number of inflammatory diseases affecting skin, eye, gums, and gastrointestinal tract in addition to the respiratory disorders such as asthma, bronchitis, and laryngitis [1].

Salai guggal or oleo-gum resin is a mixture of gum, resin, and essential oil. Hexose and pentose sugars with certain digestive and oxidizing enzymes make up the gum. Combination of some phenolics, mono-, di-, and sesqui-terpenes and a diterpene alcohol is found in the essential oil fraction. The resin part of almost all species of Boswellia is mainly made up of boswellic acid (BA), a pentacyclic triterpene acid [2,3].

A number of reviews and research papers focusing on pharmacological studies have highlighted the usefulness of BAs in the management of several chronic inflammatory diseases including chronic ulcerative colitis, rheumatoid arthritis, Crohn's disease, and bronchial asthma; in addition to its antidepressive, antianxiety, and beneficial effects in brain tumor patient [4].

The two most efficient anti-inflammatoryBAs of Boswellia are11-keto-betaBA (KBA) and acetyl-KBA (AKBA) [5]. BAs selectively inhibit leukotriene formation by inhibiting 5-lipoxygenase (5-LOX) in a non-competitive, non-redox, and enzyme-directed manner. They also exhibit various effects such as antioxidant, cancer drug sensitizing, antinociceptive, antibacterial, insulin resistance lowering, and cardioprotective.
Pharmacognostical characteristics of Indian Boswellia

Macroscopically, the oleo-gum resin occurs as transparent, brownishyellow, $2 \mathrm{~cm}$ thick, stalactic tears that constitute agglomerates of different sizes and shape, fracture, fragrant, brittle; ruptured waxy surface and translucent; and burn voluntarily and emanate an appealing characteristic, balsamic resinous odor and taste is pungent, bitterish, and slightly aromatic but agreeable. Microscopically, debris of fibers, rectangular cork, yellowish oil globules, and innumerable large or small, oval to round or rhomboidal crystalline fragments are present [6]. In general, exudate, bark, trunk, and oleo-gum resin of B. serrata are used medically [7].

In India, it is one of the most common trees found in some parts of Khandesh, Loonawara, and other neighboring territories [8]. It is a native of the mountainous parts of Coromandel, attaining a large size [9]. It is also spotted in dry hilly forest regions of Madhya Pradesh, Rajasthan, Bihar, Orissa, Assam, as well as peninsular central regions of Andhra Pradesh [10]. Table 1 gives the botanical description of the plant [11,12].

\section{Phytochemistry}

Various important phytochemicals are found in oleo-gum resin mixture. These include mucus, pure resin, and essential oil. The content and composition of oleo-gum resin may vary from species to species depending on resin's quality, age, and geographical conditions. The resins of Boswellia species chiefly contain higher terpenoids, i.e., pentacyclic triterpenes and tetracyclic triterpenes and are responsible for its pharmacological effects $[13,14]$.

The six major BAs are $\alpha$ - and $\beta$-BAs (10-21\%), KBA (2.5-7.5\%), acetylated $\alpha$ - and $\beta$-BAs $(0.05-6 \%)$, and 3-o-AKBA (0.1-3\%). The content of BAs in commercially available standardized extract varies from 37.5 to $65 \%$ [13].

The dry extract of B. serrata contains approximately $50-60 \%$ of various $\alpha$ - and $\beta$-BAs, of which $1-3 \%$ is the most bioactive AKBA fraction $[15,16]$. Among all the BAs of Boswellia, the two most active, potent, and anti-inflammatory agents are AKBA and KBA. The lipophilic part of AKBA with a $\beta$-configuration has been described to have 


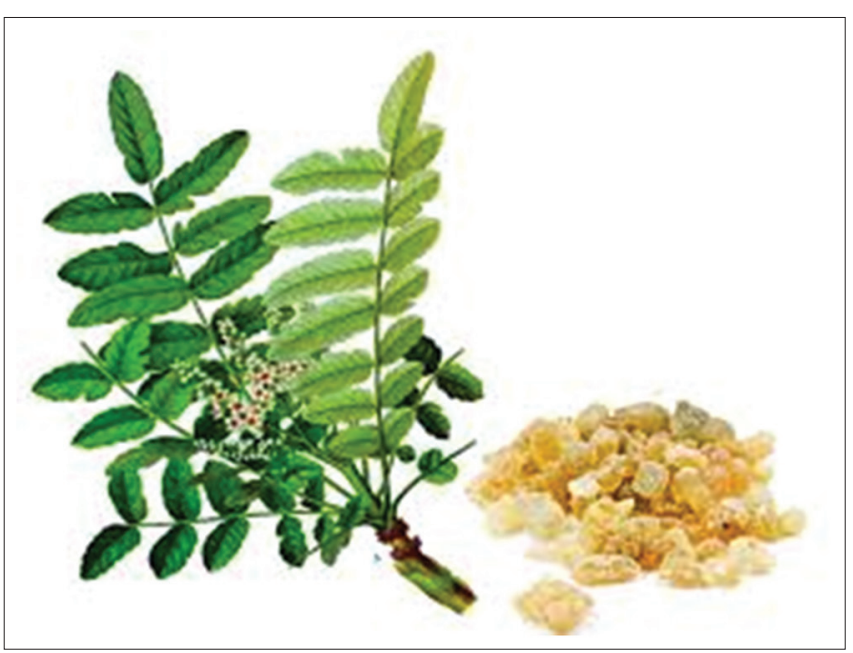

Fig. 1: Boswellia serrata

Table 1: Botanical genesis and native names of Boswellia serrata

\begin{tabular}{ll}
\hline Botanical origin & Native names \\
\hline Species: Serrata & English - Indian frankincense \\
Genus - Boswellia & Hindi - Salai, Kundur \\
Family - Burseraceae & Gujarati - Gugali, Dhup \\
Class - Anacardiales & Malayalam - Saambraani, Parangi \\
Over-class - Rutanae & Telugu - Saambraani, Phirangi \\
Subtribe - Rosidae S. lat. & Sanskrit - Kunduru, Ashvamurti, \\
& Shallaki \\
Tribe - Rosopsida & Tamil - Saambraani, Parangi \\
Sub- division- Angiospermae & Kannada- Guguladhuph, Chitta \\
Division- Spermatophyte & Bengali- Salai, Kundur \\
\hline
\end{tabular}

superior anti-inflammatory properties over $\alpha$-configuration [17]. Some other BAs isolated from Boswellia are 9, 11-dehydro- $\alpha$-BAs and its isomer and their acetylated group form. The other phytoconstituents found in Boswellia are incensole acetate, acetyl-lupeolic acid, lupeolic acid, incensole oxide, and isoincensole oxide [18-24].

Modification in chemistry of BAs alters their biological effect. When 11-keto group of BA is modified to methylene group, 5-LO activity has been observed to decrease. However, reduced form is more efficient toward induction of apoptosis and inhibition of topoisomerases. Removal of acetyl group or reduction of 11-keto group to alcohol in AKBA produces slight decrease in activity of 5-LO inhibition suggesting that the 11-keto functionality and pentacyclic triterpene ring are critical for receptor attachment to produce anti-inflammatory activity [25].

The essential oil of Salai guggul mainly contains monoterpenes such as $\alpha$-pinene (major monoterpene), trans-pinocarveol, myrcene cis-verbenol, borneol, limonene, phellandrene, cadinene, verbenone, thuja 2, 4(10)-diene, $p$-cymene, and small amount of diterpenes [26].

\section{Chemistry of various BAs}

Structures of various pentacyclic triterpenic acids (BAs) are illustrated in Fig. 2.

\section{Pharmacokinetics properties of BA}

AKBA and KBA are lipotropic fractions of BA responsible for their poor intestinal penetration and high retention [28,29]. Literature reports that the bioavailable plasma levels of various BAs were enhanced many folds by simultaneous administration of a fat-rich food [16].

Various studies to improve bioavailability of BA have been reported in literature. Recently, Bairwa and Jachak (2016) developed a polydilactide coglycoside-based nanotechnique for KBA to enhance its oral bioavailability and in vivo anti-inflammatory activity [30]. Hüsch et al. (2013) formulated B. serrata gum resin extract into Casperome, a soy lecithin formulation which showed significantly high level of KBA and $\beta$-BA fraction [31].

Sengupta et al. (2011) characterized a novel formulation called Aflapin, which consists of B. serrata extract (BSE) rich in AKBA and non-volatile oil part of B. serrata resin. In Aflapin-supplemented animals, the level of AKBA is increased by $51.78 \%$ in systemic circulation in comparison with $30 \%$ standardized AKBA extract. Aflapin showed better antiinflammatory efficacy in Freund's complete adjuvant-induced inflammation model in Sprague-Dawley rats [32].

Fartyal et al. (2011) studied floating microspheres using BA for prolongation of gastric retention time [33]. Sharma et al. (2010) studied the complexation of BA with phosphatidylcholine (PC) to enhance its bioavailability [34]. The compound showed better hypolipidemic activity and anti-inflammatory activity as compared to BA. The obtained result revealed that increased bioavailability of BA-PC complex may be due to amphiphilic nature of the complex, which, in turn, enhanced the lipid and water solubility of BAs.

Goel et al. (2010) developed AKBA-loaded polymeric nanomicelles which showed magnified antiarthritic, anti-inflammatory, and skin permeability activities [35].

\section{Mechanism of action}

The most promising targets for BAs are 5-LO, angiogenesis, topoisomerases, and cytochrome p450 enzyme (Fig. 3) [17,36-38].

\section{5-LO inhibition}

In neutrophils, 5-LO predominantly converts endogenous arachidonic acid to leukotrienes and 5-hydroxyeicosatetraenoic acid. They cause vasoconstriction, bronchospasm increased permeability and chemotaxis. BA is a unique, specific, non-redox inhibitor of 5-LO as it neither impairs the cyclooxygenase and 12-lipoxygenase enzyme properties nor inhibits the peroxidation of arachidonic acid $[17,31,34,36-46]$.

\section{Topoisomerase inhibition}

BAs have a real catalytic inhibitory action on human topoisomerase. BAs not only inhibit DNA formation in human leukemic promyelocytic cells in a dose-dependent manner but also inhibit topoisomerase through binding with the enzyme [17,41-44].

\section{Leukocyte elastase inhibition}

The human elastase decreases the elasticity of lungs, constricts the lungs passages, damages the secretion of mucus in lungs, and decreases the removal of the mucus. In addition to this, it disrupts skin cells and causes swelling, redness, and edema that are symptoms of inflammation. BAs reduce the activity of elastase enzyme which is responsible of emphysema. AKBA and KBA have been expressed to retard elastase in a dose-dependent way [44].

\section{Inhibition of $\mathrm{C} 2$ and $\mathrm{C} 3$ convertase}

BAs inhibit the C2 convertase enzyme which has the most significant role in the classical complement pathway for specific immunity [45]. BAs have been observed to inhibit hemolysis and chemotaxis of leukocytes and inhibit a crucial enzyme C-3 convertase of the classical complementary pathway $[45,47,48]$. Safayhi and Sailer reported that AKBA and KBA were the strong 5-LO inhibitors with half maximal inhibitory concentration values of $1.5 \mu \mathrm{M}$ and $3.0 \mu \mathrm{M}$, respectively $[37,49]$.

\section{Effect of BA on various organs}

BAs are characterized by their ability to act on multiple targets which are compiled in Table 2 . 


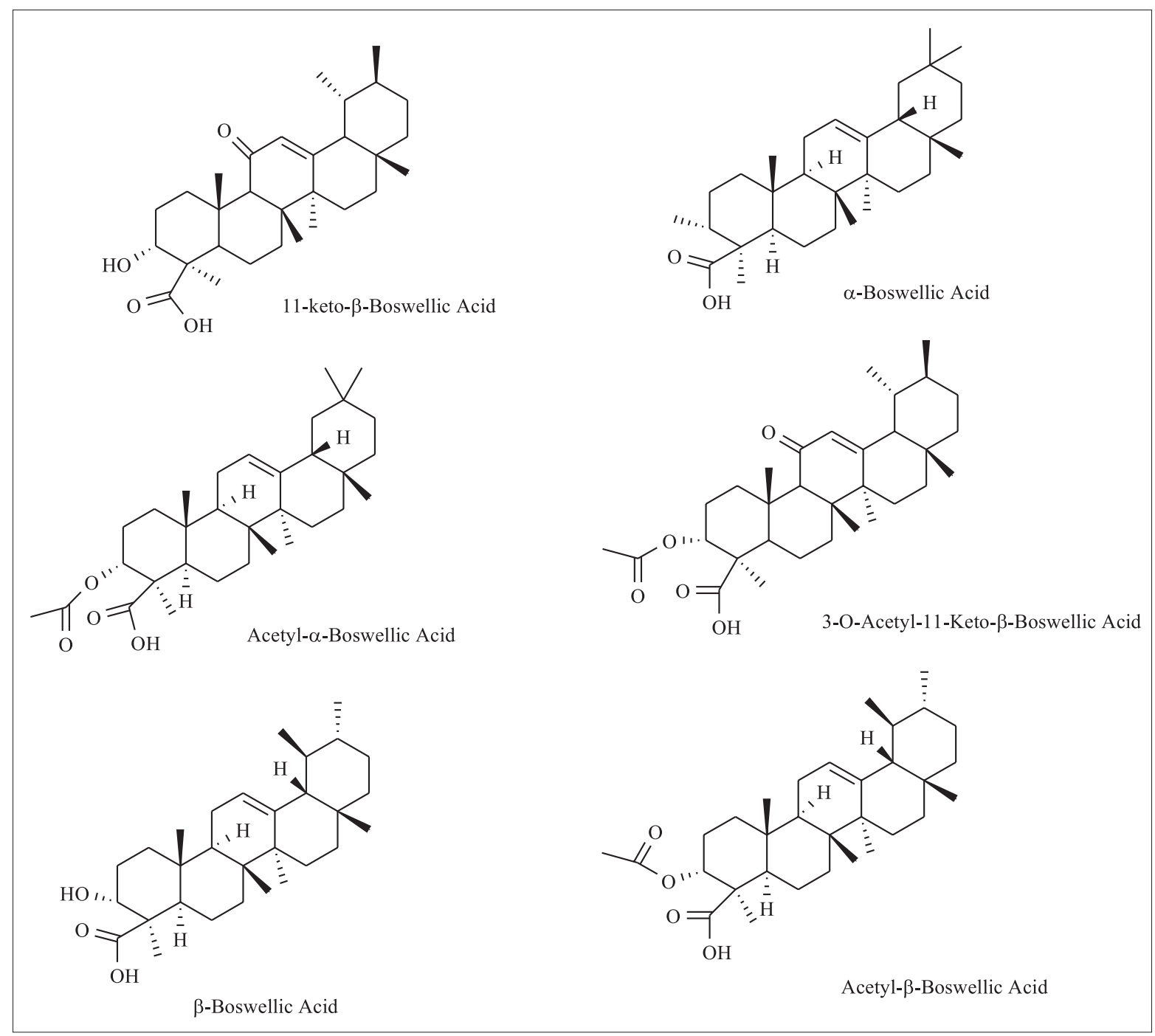

Fig. 2: Structures of various boswellic acids (pentacyclic acids) present in frankincense [27]

Table 2: Beneficial uses of Salai guggul in the standard Indian Ayurvedic system [1]

\begin{tabular}{ll}
\hline Organ and functional system & Effects \\
\hline Cardiovascular system & Cardiotonic \\
Gastrointestinal tract & Carminative \\
& Regulating color of stool \\
& Anthelmintic \\
& Improving digestion \\
Nervous system & Mental tonic \\
& Analgesic \\
Fever & Eye tonic \\
Skin & Antipyretic \\
& Increases perspiration \\
Urogenital system & Wound healing \\
Whole organism & Diuretic \\
& Improving menstruation \\
& Anti-inflammatory \\
& Antiseptic \\
\hline
\end{tabular}

Pharmacological profile of BAs

Antiarthritic and anti-inflammatory activity

Carrageenan and dextran are widely utilized to induce paw edema for screening of anti-inflammatory action of drugs. Singh and Atal observed that oral administration of an alcoholic extract of the oleo-gum resin of BS caused inhibition of the carrageenan-induced edema in rats and mice and dextran-induced edema in rats. Numerous scientific studies clearly support the privilege that BS possesses potent anti-inflammatory activity [50].

The anti-inflammatory activity of BAs is due to inhibition of leukotriene synthesis through 5-LO; however, they have no effect on cyclooxygenase, 12-lipoxygenase arachidonic acid peroxidation by ascorbate, and iron. The data demonstrated that BAs from B. serrata are specific, non-redox inhibitors of leukotriene synthesis either by interacting immediately with 5-LO or restricting its translocation and thus act as a potent antiinflammatory agent [17]. The inhibition of 5-LO by BAs that lead to decreased production of leukotrienes has received high attention by scientific society since a variety of chronic inflammatory diseases are connected with increased leukotrienes activity [51].

Extract of $B$. serrata leads to inhibition of carrageenan-induced paw edema by $39.75 \%$ and $65-73 \%$ with a dose of $50-200 \mathrm{mg} / \mathrm{kg}$ (p.o) and $50-100 \mathrm{mg} / \mathrm{kg}$ (i.p) appropriately compared to $47 \%$ inhibition seen with phenylbutazone $(50 \mathrm{mg} / \mathrm{kg}$ p.o.). The anti-inflammatory activity was equally well noted in adrenalectomized rats. Inhibition of paw swelling (34\% and $49 \%$ ) has been seen with the mycobacterial adjuvant-induced polyarthritis in rats [50].

Ammon et al. (1991) implemented studies on leukocytes migration into the inflammatory exudates induced by carrageenan. Extract of B. serrata 


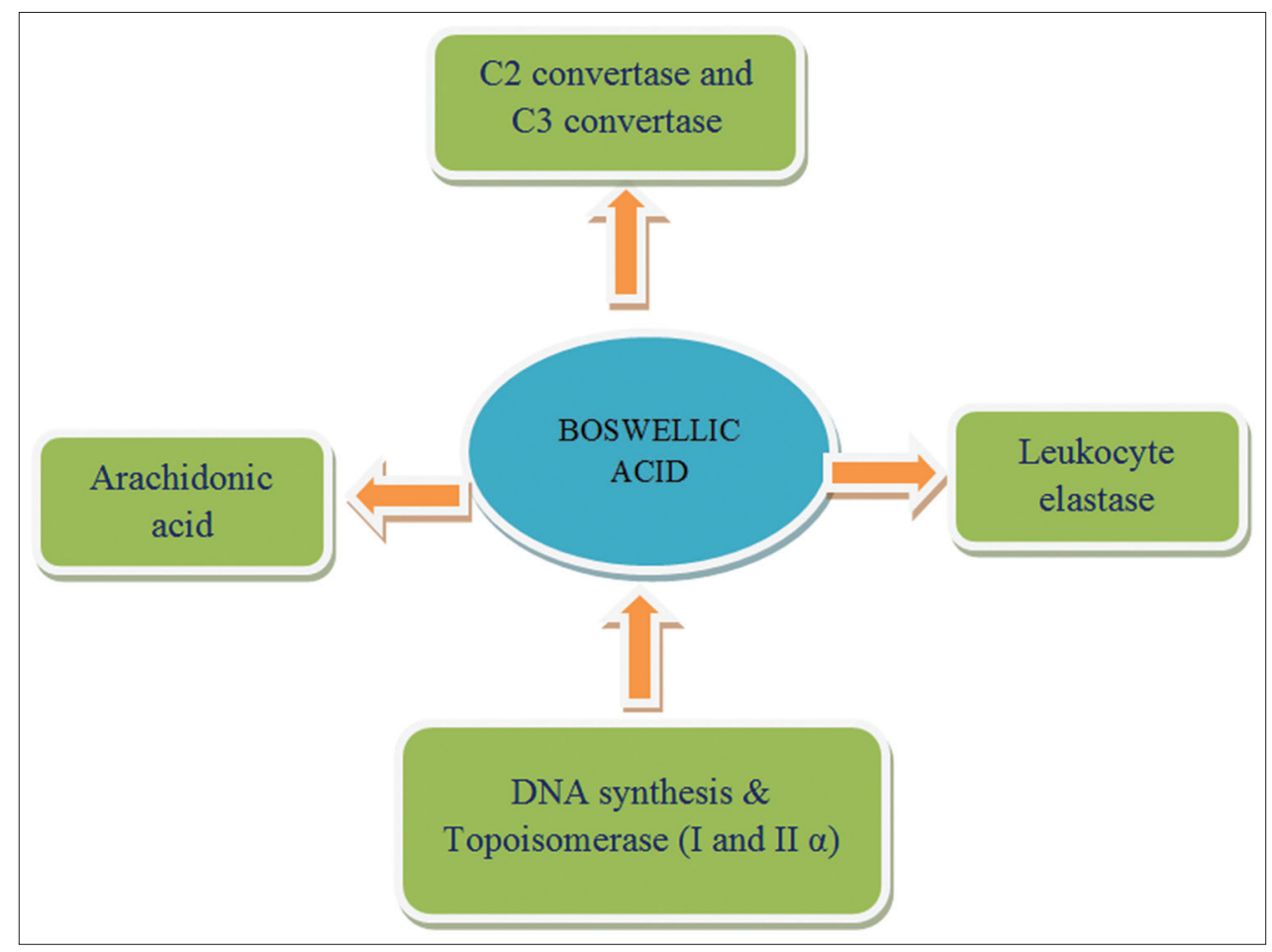

Fig. 3: Mechanism of action of boswellic acids

in dose of $100 \mathrm{mg} / \mathrm{kg}$ orally showed significant diminishing effect on both the leukocytes population and volume of pleural exudates [36]. Singh and Atal (1984) calculated the anti-inflammatory effect of mixture of BAs, and in formaldehyde arthritis model, it exhibited 45-67\% antiarthritic activity. It has been shown to be effective in adjuvant arthritis (35-59\%) as well as in established arthritis (54-84\%), also relieved fever [50]. Kulkarni et al. and Chopra et al. have conducted clinical trials for establishing anti-inflammatory properties of Boswellia, in combination with Curcuma longa, Zingiber officinale, and Withania somnifera. Treatment with this combination produced significant decrease in disability score and severity of pain [52,53].

Sharma et al., in 1989, studied the effectiveness of BA on bovine serum albumin (BSA)-induced arthritis model in rabbits. The oral administration of BA $(25,50$, and $100 \mathrm{mg} / \mathrm{kg} /$ day $)$ remarkably lessened the leukocytes in BSA-injected knee which changed the electrophoretic pattern of the synovial fluid protein [51]. Gupta et al. (1992) found BAs to be much more effective in the latex of papaya-induced model of inflammation than carrageenan-induced inflammation. In the carrageenan model, the effect of acetylsalicylic acid was compared with the action of prednisolone and BAs. This suggests that the antiinflammatory activity of BAs is different from aspirin-like drugs and prednisolone. BAs did not inhibit prostaglandin synthesis but were more effective in inhibition of leukotriene synthesis [54].

It has been also reported that BAs produce the anti-inflammatory actions in mouse macrophages and human peripheral blood mononuclear cells through inhibition of mitogen-activated protein kinases (MAPK), NO, tumor necrosis factor-alpha (TNF- $\alpha$ ), and interleukin-1 $\beta$ [55].

Khosravi et al., in 2011, organized a double-blind randomized clinical trial to assess the effectiveness of Boswellia in moderate plaqueinduced gingivitis. They reported that the Boswellia extract had the ability to lessen the inflammation of periodontium associated with plaque-induced gingivitis [56].

Notarnicola et al. assessed the effectiveness of the combination of BAmethylsulfonylmethane (MSM) in comparison to glucosamine (GS) as an effective supplement in the management of knee arthritis through a clinical trial. It was found that the BS-MSM combination showed promising and satisfactory results with respect to GS [57].

Review articles published in the past for preclinical and clinical studies have clearly highlighted and supported the anti-inflammatory activities of B. serrata.

\section{Analgesic effect}

B. serrata is used to treat muscular and arthritic pain in various systems of medicine [58-60]. Menon and Kar exhibited that the non-phenolic fraction of $B$. serrata possesses remarkable analgesic and sedative effect. They also revealed significant reduction in the spontaneous locomotor activity after treatment with Boswellia [61]. Sharma et al. investigated the analgesic activity of various fractions of $B$. serrata distinctly by formalin test, acetic acid-induced writhing, hot plate methods, and tail immersion model of analgesic in rats [60]. Both peripherally and centrally mediated analgesic action were measured. Tail immersion methods and acetic acidinduced abdominal constriction elucidated central and peripheral activity, respectively, although the formalin test measured both. Peripheral effects were elucidated by hot plate method [62]. They not only assessed the analgesic activity but also elucidated the mode of action. The oleo-gum resin fraction showed maximal inhibition $(60.54 \%)$ as compared to gum (54.88\%) and oil (20.70\%) fraction. In 2005, Bishnoi et al. examined the analgesic activity of AKBA at different dose levels by tail flick and acetic acid-induced writhing method in mice. In acetic acid-induced writhing method, a dose-dependent increase in antinociceptive activity of AKBA was shown while in tail flick method, $100 \mathrm{mg}$ of AKBA showed similar response to $200 \mathrm{mg}$. AKBA was found to be significantly better than positive control, nimesulide [63]. Al-Harrasi et al. used formalininduced pain and acetic acid-induced writhing to investigate the analgesic activity of Boswellia sacra in mice. Polar subfraction was observed with highest analgesic activity, almost double of positive control, aspirin. The study proposed that Boswellia seems to produce antinociceptive effect by both peripheral and central mechanism [64].

\section{Antifungal activity}

In a study using agar well diffusion method, Chaurasia and Gharia investigated the antifungal activity of $B$. serrata against plant pathogenic 
fungus (red rot disease-causing agent) Colletotrichum falcatum. They extracted the plant with water, ethanol, and chloroform and concluded that the ethanolic extract of plant was much more efficient than chloroform extract [65]

Garg (1974) studied antifungal activity of $B$. serrata and found that on hydrodistillation B. serrata produced $0.6 \%$ of essential oil. The oil has mild antifungal activity against human pathogens and highly effective against plant pathogens, seen by inhibition of the tested organisms, namely Phytophthora parasitica [66].

\section{Antihyperlipidemic and antidiabetic activity}

Olibanum gum resin has traditionally been used in the treatment of diabetes in patients and has been recognized with its beneficial effects in a large number of diseases. Several investigations in rat's model showed that BSE of olibanum gum resin significantly decreased total cholesterol and has potential hypolipidemic and hepatoprotective activities $[67,68]$. A study has also been carried out for comparison between olibanum resin and placebo for the curing of type 2 diabetes in double-blinded clinical trial on 71 patients. They suggested that olibanum gum resin improves glycemic control and lowers the blood levels of glucose, HbA1c, insulin, total cholesterol, and triglycerides [69].

An herbal formulation of $B$. serrata gum resin has been documented to induce powerful hypoglycemic effect by affecting hepatic gluconeogenesis and phosphoenolpyruvate carboxykinase [70]. At different dose levels (25-50 mg/kg. p.o.), the alcoholic extract exhibited antihyperlipidemic activity with hypercholesterolemic animals and lowered cholesterol (30-50\%) and triglycerides (20-60\%) levels [71]. The past studies and research clearly revealed that Boswellia is an effective antihyperlipidemic agent. Hydrophilic portion of BSE enhanced high-density lipoprotein and diminished the concentration of total cholesterol (38-48\%) in experimental animals. Zutshi et al. observed that Salai guggal retains optimum levels of serum cholesterol and triglycerides in animals, which were fed high cholesterol and saturated fat-rich diet [72]. AKBA has been exhibited to inhibit the activity of nuclear factor kappa B (NF-kB) in atherosclerosis. Liu et al. found that AKBA is known to have anti-adipocyte property by virtue of which it induces lipolysis in mature human adipocytes [73].

\section{Antimicrobial and antioxidant effects}

Ismail et al. reported that the resin extract of Salai guggal powder demonstrated microbicidal activity in different concentration ranges $(25,50,75$, and $100 \mathrm{mg} / \mathrm{ml})$ against of Gram-negative (Proteus vulgaris, Klebsiella pneumonia, Pseudomonas aeruginosa, Escherichia Coli, and Enterobacter aerogenes) and Gram-positive (Staphylococcus aureus, Bacillus subtilis, and Streptococcus pneumonia) microbes. They observed the inhibition zone and compared with antibiotic ciprofloxacin $(5 \mu \mathrm{g} / \mathrm{ml})$ as positive control and dimethyl sulfoxide as a negative control [74]

Patel and Patel evaluated the antibacterial activity of extracts of B. serrata in acetone, water, methanol, and petroleum ether on Gramnegative urinary tract infection pathogens (K. pneumonia, E. coli, $P$. vulgaris, and $P$. aeruginosa) by disk diffusion method. The acetone extract was found to have significant antibacterial activity against $K$. pneumonia and E. coli with minimum inhibitory concentration value of $12.5 \mu \mathrm{g} / \mu \mathrm{l}$ [75]. Baratta et al., 1998, studied antimicrobial and antioxidant activity and determined the essential oil of B. serrata by gas chromatography (GC) and GC-mass spectrometry. The volatile oil portion possessed significant antimicrobial activity against all the test organisms and comparable antioxidant activity to butylated hydroxytoluene and $\alpha$-tocopherol [76].

Raja et al. tested the antibacterial activity of BAs against a variety of pathogenic Gram-negative and Gram-positive bacteria and concluded that AKBA was the most potent constituent with antibacterial potential among all BAs but only against Gram-positive bacteria [77].

\section{Antiasthmatic activity}

The resins of $B$. serrata have been described to inhibit leukotriene biosynthesis and have a beneficial effect on respiratory disorders. It is used in massages, bath and treatment of cough, excessive discharge or buildup of mucus in the nose or throat, asthma, and bronchitis.

It was confirmed by Gupta et al. (1998) that alcoholic extract of B. serrata has remarkable effect in asthma. In a double-blind placebo control clinical study, they studied promising antiasthmatic effect of alcoholic extract of Salai guggal with $70 \%$ of the patients showing recovery in physical symptoms and signs of bronchitis and dyspnea. Mobilization of intracellular $\mathrm{Ca}^{2+}$ and induction of MAPK were also observed $[78,79]$.

Liu et al. investigated the antiasthmatic potential and studied the action of BA in murine model of asthma. They found that the animals treated with the BA could suppress the allergic inflammation, hyperresponsiveness, Th2 cytokines secretion, and ovalbumin-specific IgE [80]. BA was reported to reduce the infiltration of cells, lessen the demolition of lung structure, and attenuate fibrotic lungs by 5-LO inhibition action in an experimental model of pulmonary fibrosis using bleomycin [81].

\section{Antidiarrheal activity}

BAs from B. serrata were effective in controlling diarrhea without causing constipation in patients with inflammatory bowel syndrome. They also inhibited contraction of intestinal smooth muscles, thereby controlling acetylcholine and barium chloride-induced diarrhea [82].

\section{Anticancer activity}

BSE has been shown to halt the brain tumor and breast cancer metastases. BSE comprised $60 \%$ BAs have apparently repressed inflammation and tumor in mice. Antineoplastic effect has been investigated in mice with Ehrlich ascites carcinoma and S-180 tumor by interfering with the biosynthesis of DNA, RNA, and protein which caused inhibition in cell proliferation. The potency of BSE against the peritumoral edema can be magnified by enhancing the bioavailability of AKBA [2]

B. serrata showed antitumor effect in diverse types of tumor cells including prostate, colon, leukocytes, brain, and liver. AKBA was found with an inhibitory effect on NF-kB and also potentiated apoptosis and inhibition of angiogenesis in neoplastic cells by signaling transducer pathway and activation of transcription 3-related pathways [43,83-88].

In addition to this, Sinha et al. showed in vivo Matrigel plug assay that BAs inhibit basic fibroblast growth factor-induced angiogenesis [89].

Ahmed et al. studied the potency of B. serrata methylene chloride extract against colon cancer induced in animals and also evaluated the serum epidermal growth factor, matrix metalloproteinase (MMP)-9, MMP-7, plasma transforming growth factor- $\beta$ (TGF- $\beta$ ), and TNF- $\alpha$ levels using ELISA. Cyclin D1 and colon cyclooxygenase-2 (COX-2) expressions were estimated by immunohistochemical technique. Colon cancer group was found with sufficient elevation in cyclin D1 and COX-2 expressions in colon cells, whereas all treatment groups showed marked decrease in cyclin D1 and COX-2 expression. This study reflected the therapeutic role of B. serrata against colon carcinoma developed in rats [90].

Pang et al. prepared BA nanoparticle formulation for the treatment of prostate cancer. BA nanoparticles caused DNA fragmentation, which is a hallmark of apoptosis [85].

McCarty reported BAs as cancer chemopreventive agents and was found to lessen tumor cell invasiveness and tumor cell motility, to moderate tumor development, and to reduce tumor angiogenesis [91].

\section{Anticomplementary activity}

In a study of antibody-coated sheep erythrocytes by pooled guinea pig serum, BAs have been found to inhibit immunohemolysis. Retardation 
of the C3-convertase enzyme with a threshold concentration of $100 \mu \mathrm{g}$ of the classical complement pathway caused decreased in immunohemolysis. BA has also showed hindering effect on guinea pig serum by in vivo technique [92].

BAs were also found to inhibit hemolysis and chemotaxis of leukocytes and were shown to work by inhibiting the key enzyme of the classical complementary pathway, namely C3-convertase, a serine protease $[45,47,48]$ and were found to possess anticomplementary activity.

\section{Clastogenic activity}

The consumption of Boswellia serrata is believed to improve memory, learning, performance, and cognitive behavior. It is also recommended for pregnant women to raise the intelligence and memory of their offsprings [93]. Aqueous extract of B. serrata, W. somnifera, and Spirulina alga produced clastogenic effect and was found to be effective in stress relief and memory boost. All these results were recognized to be dose dependent and may be due to the binding of BAs with neurotransmitter signaling pathways or protein kinase pathways in brain [94].

\section{Antidepressant activity}

B. serrata has been reported to be efficient in acute model of depression. Prabhakar et al. showed that at a dose of $100 \mathrm{mg} / \mathrm{kg}$, B. serrata has notable antidepressant activity in acute models of depression and that they lessen the immobility period in forced swim experimental model [95].

\section{Branded formulations containing B. serrata [1]}

Apart from its use in spiritual ceremonies, Boswellia has been practiced as an important adhesive in lotions, creams, perfumes, and detergents, with an oriental note in its scent, in prominent products of the perfume and cosmetic industry. Many preparations with $B$. serrata are assessable in the markets which are elaborated below:

- $\quad$ Boswellin $^{\circledR}$, a certified trademark by Sabinsa Corporation was popularized in the US and European markets in 1991. It is available in tablet or capsule forms and also in a calming pain diminishing cream consisting capsaicin. Product comprises BAs ranging from 150 to $250 \mathrm{mg}$ /capsule or tablet, to be taken orally twice to thrice a day.

- $\quad$ Niltan ${ }^{\circledR}$ is a cream formulation for external use, produced by Dr. Reddy's Laboratories Limited, Hyderabad. It is a unification of active herbal extracts (arbutin, boswellin, coriander seed oil, and liquorice extract in a semisolid base). It imparts its action by reducing the enzyme tyrosinase in the skin, also diminishing the level of melanin, which is responsible for darkness of skin.

- $\quad S h a l l a k i^{\circledR}$, each capsule consists of $125 \mathrm{mg}$ B. serrata. It has certified anti-inflammatory and analgesic effects advantageous in relieving joint pains, produced by Himalayan Company, Makali, Bengaluru.

- $\quad$ Rheumatic- $X^{\circledR}$ consists of 20 mg "Shallaki” along with a number of ingredients, produced by Sunrise Herbals, Banaras (U.P., India), and prescribed for osteoarthritis, gout, rheumatoid, and pain.

\section{CONCLUSION}

The present review focuses on the scientific recognition of the remedial usefulness and action of $B$. serrata once used in cultural and religious ceremonies but now valued for its numerous beneficial medicinal effects. BAs are the bioactive phytoconstituents which have demonstrated promising results in numerous experiments and clinical studies. Their medicinal properties are also widely recognized for the treatment of ailments ranging from inflammatory conditions, microbial infections to cancer. In addition to this, its products have been recommended for topical use in the treatment of chronic and excessively damaged skin. Future challenges are toward understanding the drug-drug interactions, molecular mechanism, and development of strategies to improve their pharmacokinetic profile.

\section{AUTHORS' CONTRIBUTIONS}

Nameeta Pilkhwal; Department of Pharmacology, Amity Institute of Pharmacy, Amity University, Lucknow Campus, has searched the databases, collected, compiled, analyzed the data, and drafted the review article.

Prof. (Dr.) Suneela S. Dhaneshwar; Director, Amity Institute of Pharmacy, Deputy Dean of Research (S \& T), Amity University, Lucknow Campus, has guided Ms. Nameeta for writing this review article and also critically reviewed, redrafted, and revised the same.

\section{CONFLICTS OF INTEREST}

Authors have no conflicts of interest to declare.

\section{REFERENCES}

1. Siddiqui MZ. Boswellia serrata, a potential antiinflammatory agent: An overview. Indian J Pharm Sci 2011;73:255-61.

2. Shah BA, Qazi GN, Taneja SC. Boswellic acids: A group of medicinally important compounds. Nat Prod Rep 2009;26:72-89.

3. Hamidpour R, Hamidpour S, Hamidpour M, Shahlari M. Frankincense (rǔ xiāng; Boswellia species): From the selection of traditional applications to the novel phytotherapy for the prevention and treatment of serious diseases. J Tradit Complement Med 2013;3:221-6.

4. Zhang Y, Ning Z, Lu C, Zhao S, Wang J, Liu B, et al. Triterpenoid resinous metabolites from the genus Boswellia: Pharmacological activities and potential species-identifying properties. Chem Cent J 2013;7:153.

5. Du Z, Liu Z, Ning Z, Liu Y, Song Z, Wang C, et al. Prospects of boswellic acids as potential pharmaceutics. Planta Med 2015;81:259-71.

6. Ammon HP. Modulation of the immune system by Boswellia serrata extracts and boswellic acids. Phytomedicine 2010;17:862-7.

7. Herrmann A, König S, Lechtenberg M, Sehlbach M, Vakhrushev SY, Peter-Katalinic J, et al. Proteoglycans from Boswellia serrata roxb. and B. carteri birdw. And identification of a proteolytic plant basic secretory protein. Glycobiology 2012;22:1424-39.

8. Ammon HP. Boswellic Acid in Chronic Inflammatory Disease. Pharmacologi Univesitat Tubingen; 2006. Available from: http://www. indianboswellia.com/pdf/Prof Ammon Research.pdf. [Last accessed on 2014 Aug 27].

9. Birkner KM. Boswellia, the Pain Herb. San Antonio, Texas: Pain and Stress Publications; 2006.

10. Upaganlawar A, Ghule B. Pharmacological activities of Boswellia serrate roxb. - Mini review. Ethnobotanical Leaflets 2009:13:766-74.

11. Sultana A, Takaoka J, Koga T. Boswellia serrate roxb. A traditional herb with versatile pharmacological activity: A review. Int J Pharm Sci Res 2013;4:2106-17.

12. Alam M, Khan H, Samiullah L, Siddique KM. Areview on phytochemical and pharmacological studies of Kundur (Boswellia serrate Roxb ex Colebr.) - A Unani drug. J Appl Pharm Sci 2012;2:148-56.

13. Gerbeth K, Meins J, Kirste S, Momm F, Schubert-Zsilavecz M, AbdelTawab M. Determination of major boswellic acids in plasma by highpressure liquid chromatography/mass spectrometry. J Pharm Biomed Anal 2011;56:998-1005.

14. Al-Harrasi A, Ali L, Rehman NU, Hussain H, Hussain J, AlRawahi A, et al. Nine triterpenes from Boswellia sacra Fluckiger and their chemotaxonomic importance. Biochem Syst Ecol 2013;51:113-6.

15. Sterk V, Bu Chele B, Simmet T. Simultaneous food intake enhances the bioavailability of frankincensebased phytopharmaceuticals. Zeitschrift Phytother 2005;26:174-80.

16. Sterk V, Büchele B, Simmet T. Effect of food intake on the bioavailability of boswellic acids from a herbal preparation in healthy volunteers. Planta Med 2004;70:1155-60.

17. Poeckel D, Werz O. Boswellic acids: Biological actions and molecular targets. Curr Med Chem 2006;13:3359-69.

18. Wang C, Xia L, Song Z, Li Q, Wang C, Zeng L, et al. Determination of five boswellic acids in Boswellia serrata. Zhongguo Zhong Yao Za Zhi 2011;36:1330-3.

19. Moussaieff A, Gross M, Nesher E, Tikhonov T, Yadid G, Pinhasov A. Incensole acetate reduces depressive-like behavior and modulates hippocampal BDNF and CRF expression of submissive animals. J Psychopharmacol 2012;26:1584-93.

20. Paul M, Jauch J. Efficient preparation of incensole and incensole acetate, 
and quantification of these bioactive diterpenes in Boswellia papyrifera by a RP-DAD-HPLC method. Nat Prod Commun 2012;7:283-8

21. Bhushan S, Malik F, Kumar A, Isher HK, Kaur IP, Taneja SC, et al. Activation of p53/p21/PUMA alliance and disruption of PI-3/Akt in multimodal targeting of apoptotic signaling cascades in cervical cancer cells by a pentacyclic triterpenediol from Boswellia serrata. Mol Carcinog 2009;48:1093-108.

22. Schmidt TJ, Kaiser M, Brun R. Complete structural assignment of serratol, a cembrane-type diterpene from Boswellia serrata, and evaluation of its antiprotozoal activity. Planta Med 2011;77:849-50.

23. Morikawa T, Oominami H, Matsuda H, Yoshikawa M. New terpenoids, olibanumols D-G, from traditional Egyptian medicine olibanum, the gum-resin of Boswellia carterii. J Nat Med 2011;65:129-34.

24. Song Z, Xia L, Wei Z, Cao Y, Zhang L, Liu Z. Determination of alphapinene and octyl acetate contents in Boswellia serrata. Zhongguo Zhong Yao Za Zhi 2012;37:1431-3.

25. Sailer ER, Subramanian LR, Rall B, Hoernlein RF, Ammon HP, Safayhi H. Acetyl-11-keto-beta-boswellic acid (AKBA): Structure requirements for binding and 5-lipoxygenase inhibitory activity. $\mathrm{Br} \mathrm{J}$ Pharmacol 1996;117:615-8.

26. Al-Harrasi A, Al-Saidi S. Phytochemical analysis of the essential oil from botanically certified oleogum resin of Boswellia sacra (Omani luban). Molecules 2008;13:2181-9.

27. Kreck C, Saller R. Indidcher weihrauch und seine zubereitungen einschliesslich H15 als traditionelles und modernes Therpeutikun. Internist Prax 1998;38:857-72.

28. Büchele B, Zugmaier W, Simmet T. Analysis of pentacyclic triterpenic acids from frankincense gum resins and related phytopharmaceuticals by high-performance liquid chromatography. Identification of lupeolic acid, a novel pentacyclic triterpene. J Chromatogr B Analyt Technol Biomed Life Sci 2003;791:21-30.

29. Sharma S, Thawani V, Hingorani L, Shrivastava M, Bhate VR, Khiyani R. Pharmacokinetic study of 11-keto beta-boswellic acid. Phytomedicine 2004;11:255-60.

30. Bairwa K, Jachak SM. Nanoparticle formulation of 11-keto- $\beta$-boswellic acid (KBA): Anti-inflammatory activity and in vivo pharmacokinetics. Pharm Biol 2016;54:2909-16.

31. Hüsch J, Bohnet J, Fricker G, Skarke C, Artaria C, Appendino G, et al. Enhanced absorption of boswellic acids by a lecithin delivery form (Phytosome(®)) of Boswellia extract. Fitoterapia 2013;84:89-98.

32. Sengupta K, Kolla JN, Krishnaraju AV, Yalamanchili N, Rao CV, Golakoti $\mathrm{T}$, et al. Cellular and molecular mechanisms of antiinflammatory effect of aflapin: A novel Boswellia serrata extract. Mol Cell Biochem 2011;354:189-97.

33. Fartyal S, Jha SK, Karchuli MS, Gupta R, Vajpayee A. Formulation and evaluation of floating microspheres of boswellic acid. Int J Pharm Tech Res 2011;3:76-81.

34. Sharma A, Gupta NK, Dixit VK. Complexation with phosphatidyl choline as a strategy for absorption enhancement of boswellic acid. Drug Deliv 2010;17:587-95.

35. Goel A, Ahmad FJ, Singh RM, Singh GN. 3-acetyl-11-ketobeta-boswellic acid loaded-polymeric nanomicelles for topical anti-inflammatory and anti-arthritic activity. J Pharm Pharmacol 2010;62:273-8.

36. Ammon HP, Mack T, Singh GB, Safayhi H. Inhibition of leukotriene B4 formation in rat peritoneal neutrophils by an ethanolic extract of the gum resin exudate of Boswellia serrata. Planta Med 1991;57:203-7.

37. Safayhi H, Mack T, Sabieraj J, Anazodo MI, Subramanian LR, Ammon HP. Boswellic acids: Novel, specific, nonredox inhibitors of 5-lipoxygenase. J Pharmacol Exp Ther 1992;261:1143-6.

38. Kumar A, Shah BA, Singh S, Hamid A, Singh SK, Sethi VK, et al. Acyl derivatives of boswellic acids as inhibitors of NF- $\kappa$ B and STATs. Bioorg Med Chem Lett 2012;22:431-5.

39. Skarke C, Kuczka K, Tausch L, Werz O, Rossmanith T, Barrett JS, et al. Increased bioavailability of 11 -keto- $\beta$-boswellic acid following single oral dose frankincense extract administration after a standardized meal in healthy male volunteers: Modeling and simulation considerations for evaluating drug exposures. J Clin Pharmacol 2012;52:1592-600.

40. Hüsch J, Gerbeth K, Fricker G, Setzer C, Zirkel J, Rebmann H, et al. Effect of phospholipid-based formulations of Boswellia serrata extract on the solubility, permeability, and absorption of the individual boswellic acid constituents present. J Nat Prod 2012;75:1675-82.

41. Gerbeth K, Hüsch J, Fricker G, Werz O, Schubert-Zsilavecz M, AbdelTawab M. In vitro metabolism, permeation, and brain availability of six major boswellic acids from Boswellia serrata gum resins. Fitoterapia 2013;84:99-106.

42. Krüger P, Daneshfar R, Eckert GP, Klein J, Volmer DA, Bahr U, et al.
Metabolism of boswellic acids in vitro and in vivo. Drug Metab Dispos 2008;36:1135-42.

43. Takada Y, Ichikawa H, Badmaev V, Aggarwal BB. Acetyl-11-ketobeta-boswellic acid potentiates apoptosis, inhibits invasion, and abolishes osteoclastogenesis by suppressing NF-kappa B and NF-kappa B-regulated gene expression. J Immunol 2006;176:3127-40.

44. Safayhi H, Rall B, Sailer ER, Ammon HP. Inhibition by boswellic acids of human leukocyte elastase. J Pharmacol Exp Ther 1997;281:460-3.

45. Knaus U, Wagner H. Effect of boswellic acid of Boswellia serrata and other triterpenic acids on the complement system. Phytomedicine 1990;3:77-80.

46. Huang MT, Badmaev V, Ding Y, Liu Y, Xie JG, Ho CT, et al. Antitumor and anti-carcinogenic activities of triterpenoid, beta-boswellic acid. Biofactors 2000;13:225-30.

47. Kapil, A. Anti-complementary activity of boswellic acids, Chem Biol Herbal Med 1997;10:175-84.

48. Sharma ML, Khajuria A, Kaul A, Singh S, Singh GB, Atal CK. Effect of Salai guggal ex-Boswellia serrata on cellular and humoral immune responses and leucocyte migration. Agents Actions 1988;24:161-4.

49. Safayhi H, Sailer ER, Ammon HP. 5-lipoxygenase inhibition by acetyl-11-keto- $\beta$-boswellic acid (AKBA) by a novel mechanism. Phytomedicine 1996;3:71-2.

50. Singh GB, Atal CK. Pharmacology of an extract of salai guggul ex. Boswellia serrata. Indian J Pharmacol 1984;16:51.

51. Sharma ML, Bani S, Singh GB. Anti-arthritic activity of boswellic acids in bovine serum albumin (BSA)-induced arthritis. Int $\mathrm{J}$ Immunopharmacol 1989;11:647-52.

52. Kulkarni RR, Patki PS, Jog VP, Gandage SG, Patwardhan B. Treatment of osteoarthritis with a herbomineral formulation: A double-blind, placebo-controlled, cross-over study. J Ethnopharmacol 1991;33:91-5.

53. Chopra A, Lavin P, Patwardhan B, Chitre D. Randomized double blind trial of an ayurvedic plant derived formulation for treatment of rheumatoid arthritis. J Rheumatol 2000;27:1365-72.

54. Gupta OP, Sharma N, Chand D. A sensitive and relevant model for evaluating anti-inflammatory activity-papaya latex-induced rat paw inflammation. J Pharmacol Toxicol Methods 1992;28:15-9.

55. Gayathri B, Manjula N, Vinaykumar KS, Lakshmi BS, Balakrishnan A. Pure compound from Boswellia serrata extract exhibits antiinflammatory property in human PBMCs and mouse macrophages through inhibition of TNFalpha, IL-1beta, NO and MAP kinases. Int Immunopharmacol 2007;7:473-82.

56. Khosravi Samani M, Mahmoodian H, Moghadamnia A, Poorsattar Bejeh Mir A, Chitsazan M. The effect of frankincense in the treatment of moderate plaque-induced gingivitis: A double blinded randomized clinical trial. Daru 2011;19:288-94

57. Notarnicola A, Maccagnano G, Moretti L, Pesce V, Tafuri S, Fiore A, et al. Methylsulfonylmethane and boswellic acids versus glucosamine sulfate in the treatment of knee arthritis: Randomized trial. Int $\mathrm{J}$ Immunopathol Pharmacol 2016;29:140-6.

58. Al-Harrasi A, Al-Rawahi A, Hussain J, Ali L, Hussain H, Rehman N, et al. First in vitro lipid peroxidation and in vivo antiinflammatory activity of the Omani frankincense of Boswellia sacra flueck. Int J Phytomed 2013;5:73-7.

59. Mothana RA. Anti-inflammatory, antinociceptive and antioxidant activities of the endemic Soqotraen Boswellia elongata balf. F. and Jatropha unicostata balf. F. In different experimental models. Food Chem Toxicol 2011;49:2594-9.

60. Sharma A, Bhatia S, Kharya MD, Gajbhiye V, Ganesh N, Namdeo AG, et al. Anti-inflammatory and analgesic activity of different fractions of Boswellia serrate. Int J Phytomed 2010;2:94-9.

61. Menon MK, Kar A. Analgesic and psychopharmacological effects of the gum resin of Boswellia serrata. Planta Med 1971;19:333-41.

62. Vongtau HO, Abbah J, Ngazal IE, Kunle OF, Chindo BA, Otsapa PB, et al. Anti-nociceptive and anti-inflammatory activities of the methanolic extract of Parinari polyandra stem bark in rats and mice. J Ethnopharmacol 2004;90:115-21.

63. Bishnoi M, Patil CS, Kumar A, Kulkani SK. Analgesic activity of acetyl-11-keto-b-boswellic acid, a lipooxygenase - Enzyme inhibitor. Indian J Pharmacol 2005;37:255-6.

64. Al-Harrasi A, Ali L, Hussain J, Rehman NU, Ahmed M, AlRawahi A. Analgesic effects of crude extracts and fractions of Omani frankincense obtained from traditional medicinal plant Boswellia sacra on animal models. Asian Pac J Trop Med 2014;7:S485-90.

65. Chaurasia A, Gharia A. Antifungal activity of medicinal plant Boswellia serrata. J Ultra Chem 2017;13:88-90.

66. Garg SC. Antifungal activity of some essential oils. Indian J Pharmacol 1974;36:47. 
67. Zutsi U, Rao PG, Kaur S. Mechanism of cholesterol lowering effect of Salai guggal ex-Boswellia serrata Roxb. Indian J Pharmacol 1986;18:182-3.

68. Gerlach U. Sorbitol dehydrogenase. In: Bergmeyer HU, editor. Methods of Enzymatic Analysis. $3^{\text {rd }}$ ed. Weinheim: Verlag Chemie; 1983. p. 112-7.

69. Azadmehr A, Ziaee A, Ghanei L, Fallah Huseini H, Hajiaghaee R, Tavakoli-Far B, et al. A randomized clinical trial study: Anti-oxidant, anti-hyperglycemic and anti-hyperlipidemic effects of Olibanum gum in type 2 diabetic patients. Iran J Pharm Res 2014;13:1003-9.

70. Shehata AM, Quintanilla-Fend L, Bettio S, Singh CB, Ammon HP. Prevention of multiple low-dose streptozotocin (MLD-STZ) diabetes in mice by an extract from gum resin of Boswellia serrata (BE). Phytomedicine 2011;18:1037-44.

71. Zutshi U, Siddiqui M, Singh GB, Atal CK. Mechanism of Action of Salai Guggul as Antilipidmic, Agent Souvenier, $13^{\text {th }}$ Indian Pharmacological Society, Conference; 1980. p. 1-31.

72. Zutshi U, Rao PG, Samagat K, Singh GB, Atal CK. Mechanism of cholesterol lowering effect of Salai guggal ex- Boswellia serrata. Indian J Pharm 1980;12:59.

73. Liu JJ, Toy WC, Liu S, Cheng A, Lim BK, Subramaniam T, et al. Acetyl-keto- $\beta$-boswellic acid induces lipolysis in mature adipocytes. Biochem Biophys Res Commun 2013;431:192-6.

74. Ismail1 SM, Aluru S, Sambasivarao KR, Matcha B. Antimicrobial activity of frankincense of Boswellia serrata. Int J Curr Microbiol Appl Sci 2014;3:1095-101.

75. Patel NB, Patel KC. Antibacterial activity of Boswellia serrata roxb. Ex colebr. ethanomedicinal plant against gram negative UTI pathogens. Res Gate 2014;53:976-1098.

76. Baratta MT, Dorman HJ, Deans SG, Figueiredo AC, Barroso JG, Ruberto G. Antimicrobial and antioxidant properties of some commercial essential oils. Flavour Fragrance J 1998;13:235-40.

77. Raja AF, Ali F, Khan IA, Shawl AS, Arora DS, Shah BA, et al. Antistaphylococcal and biofilm inhibitory activities of acetyl-11-keto$\beta$-boswellic acid from Boswellia serrata. BMC Microbiol 2011;11:54.

78. Gupta I, Gupta V, Parihar A, Gupta S, Ludtke R, Safayhi H, Ammon HP. Effect of Boswellis serrata gum resin in bronchial asthma. Eur J Med Res 1998;3:511-4.

79. Miller AL. Effects of Boswellia serrata on asthma. Altern Med Rev 2001;6:20-47.

80. Liu Z, Liu X, Sang L, Liu H, Xu Q, Liu Z, et al. Boswellic acid attenuates asthma phenotypes by downregulation of GATA3 via pSTAT6 inhibition in a murine model of asthma. Int J Clin Exp Pathol 2015;8:236-43.

81. Ali EN, Mansour SZ. Boswellic acids extract attenuates pulmonary fibrosis induced by bleomycin and oxidative stress from gamma irradiation in rats. Chin Med 2011;6:36.
82. Borrelli F, Capasso F, Capasso R, Ascione V, Aviello G, Longo R, et al. Effect of Boswellia serrata on intestinal motility in rodents: Inhibition of diarrhoea without constipation. Br J Pharmacol 2006;148:553-60.

83. Liu JJ, Huang B, Hooi SC. Acetyl-keto-beta-boswellic acid inhibits cellular proliferation through a p21-dependent pathway in colon cancer cells. Br J Pharmacol 2006;148:1099-107.

84. Lu M, Xia L, Hua H, Jing Y. Acetyl-keto-beta-boswellic acid induces apoptosis through a death receptor 5-mediated pathway in prostate cancer cells. Cancer Res 2008;68:1180-6.

85. Pang X, Yi Z, Zhang X, Sung B, Qu W, Lian X. Acetyl-11-keto-betaboswellic acid inhibits prostate tumor growth by suppressing vascular endothelial growth factor receptor 2-mediated angiogenesis. Cancer Res 2009;69:5893-900.

86. Hostanska K, Daum G, Saller R. Cytostatic and apoptosis-inducing activity of boswellic acids toward malignant cell lines in vitro. Anticancer Res 2002;22:2853-62.

87. Liu JJ, Nilsson A, Oredsson S, Badmaev V, Duan RD. Keto- and acetyl-keto-boswellic acids inhibit proliferation and induce apoptosis in Hep G2 cells via a caspase-8 dependent pathway. Int J Mol Med 2002;10:501-5.

88. Glaser T, Winter S, Groscurth P, Safayhi H, Sailer ER, Ammon HP. Boswellic acids and malignant glioma: Induction of apoptosis but no modulation of drug sensitivity. Br J Cancer 1999;80:756-65.

89. Sinha VR, Singh A, Singh S, Bhinge JR. Compression coated systems for colonic delivery of 5-fluorouracil. J Pharm Pharmacol 2007;59:359-65

90. Ahmed HH, Rahman MA, Zahraa F, Shalby A, Lokman MS. Antitumor efficacy of Boswellia serrata extract in management of colon cancer induced in experimental animal. Int J Pharm Sci 2013;3:379-89.

91. McCarty MF. Targeting multiple signaling pathways as a strategy for managing prostate cancer: Multifocal signal modulation therapy. Integr Cancer Ther 2004;3:349-80.

92. Kapil A, Moza N. Anticomplementary activity of boswellic acids - an inhibitor of $\mathrm{C} 3$-convertase of the classical complement pathway. Int $\mathrm{J}$ Immunopharmacol 1992;14:1139-43.

93. Hosseini M, Hadjzadeh MA, Derakhshan M, Havakhah S, Rassouli FB, Rakhshandeh $\mathrm{H}$, et al. The beneficial effects of olibanum on memory deficit induced by hypothyroidism in adult rats tested in Morris water maze. Arch Pharm Res 2010;33:463-8.

94. Mahmoudi A, Hosseini-Sharifabad A, Monsef-Esfahani HR, Yazdinejad AR, Khanavi M, Roghani A, et al. Evaluation of systemic administration of Boswellia papyrifera extracts on spatial memory retention in male rats. J Nat Med 2011;65:519-25.

95. Prabhakar A, Chandrashekar R, Rao SN. Evaluation of antidepressant activity of Boswellia serrata in Swiss albino mice by forced swim test. Int J Univ Pharm Biosci 2013;2:417-24. 